\title{
A Place Between School and Home: Exploring the Place of Shadow Education in Students' Academic Lives in the Netherlands
}

\author{
Daury Jansen, Louise Elffers, \\ Monique L. L. Volman \\ University of Amsterdam, Research Institute of Child Development and Education
}

\begin{abstract}
Worldwide, the use of private supplementary tutoring, commonly referred to as shadow education, has become increasingly prevalent since the turn of the millennium. Recently, participation rates in the Netherlands have substantially increased. This paper aims to explore the place of shadow education in students' academic lives by studying the goals and experienced benefits that students identify. Data were collected through 37 semi-structured interviews with tutored students in secondary education in the Netherlands. Our findings indicate that students conceived of shadow education as a skill-building institution to which they turned to for self-study, to receive career support, and to boost their performance. Students' reflections reveal that shadow education builds upon and extends, but does not replace, learning activities at home and school. Based on our findings, we discuss how shadow education can function as a "third place" between school and home, occupying an increasingly prominent position in students' academic lives.
\end{abstract}

Keywords: shadow education, students' goals, experienced benefits, semi-structured interviews

When the school bell rings in the Netherlands, an increasing number of students head to private supplementary tutoring (CBS Statistics Netherlands, 2020), mirroring a pattern of increasing participation in so-called "shadow education" that is found in many countries across the globe. Like a shadow following a person or an object, shadow education follows mainstream education by providing students with formal, private, out-of-school learning activities to enhance their academic performance (Kim \& Jung, 2019). In some countries, mainly in East Asian societies which value Confucian traditions of effort and achievement, shadow education is regarded as a standard educational practice for most school-aged children (Bray, 2009). In other countries, particularly those with well-established, state-funded educational systems like the Netherlands, shadow education has long been a relatively marginal phenomenon, yet seems to be emerging as a more regular educational practice nowadays. For instance, in 2018, parents in the Netherlands spent a total of 284 million euros on shadow education, a marked increase from 26 million euros in 1995 (CBS Statistics Netherlands, 2020).

Given its increasing status, shadow education in the Netherlands is prone to varying interpretations of what goals shadow education caters to and what shadow 
40 education offers that regular educational settings may not, or cannot, offer. Policy makers, for instance, often interpret shadow education as an indication of the underperformance of schools, inferring that parents and students use shadow education to compensate for failing schools (Bray, 2009). Parents, in particular those in school systems where students are separated based on ability, can seek competitive advantage for their children through shadow education (Matsuoka, 2019). As less affluent parents may not be able to afford shadow education, concerns are that the growing use of shadow education enhances socioeconomic disparities in educational trajectories. Such concerns may fuel the need for empirical efforts exploring to what extent, and why, shadow education possibly competes with, supplements, or replaces learning activities at school (Elffers et al., 2019; Kwo \& Bray, 2014).

Whereas existing explorative research in the Netherlands focuses on how policy makers, parents, and educators interpret shadow education (Bisschop, van den Berg, \& van der Ven, 2019), scant attention has been paid to how students interpret their shadow education attendance. Therefore, this paper aims to explore the place shadow education, as a learning space, has in students' daily academic lives. We conceptualise shadow education both as a physical place that students can turn to next to their school and home environment, as well as a symbolic place to which student attach certain meanings that may or may not be unique to shadow education as a place for learning and support. By asking students to reflect on the goals they pursue and the benefits they perceive from attending shadow education, we try to unravel what it is that students seek and find in shadow education in comparison to the home and school context. Our examination of students' goals and benefits not only builds upon and extends earlier student-centred work on shadow education in Asian and North-American contexts (Chan \& Bray, 2014; Forsey, 2013; Hajar, 2018, 2019; Kim \& Jung, 2019; Mahmud, 2019), but can also enhance our understanding of the relatively unknown position shadow education occupies in students' academic lives.

\section{Conceptual framework}

In pursuit of the above-mentioned aim, we apply an institutional approach, whereby we explore the place of the shadow education institution in the academic lives of students through interviews with such students (Burman \& Miles, 2020; Yamato \& Zhang, 2017). Rather than providing an exhaustive list of factors that may or may not influence students' goals and experienced benefits (cf. Guill, Lüdtke, \& Schwanenberg, 2019; Yung \& Chiu, 2020), in this section, we examine what students' goals and experienced benefits can be, and how such goals and benefits are indicative of interrelationships between institutions (Figure 1). 


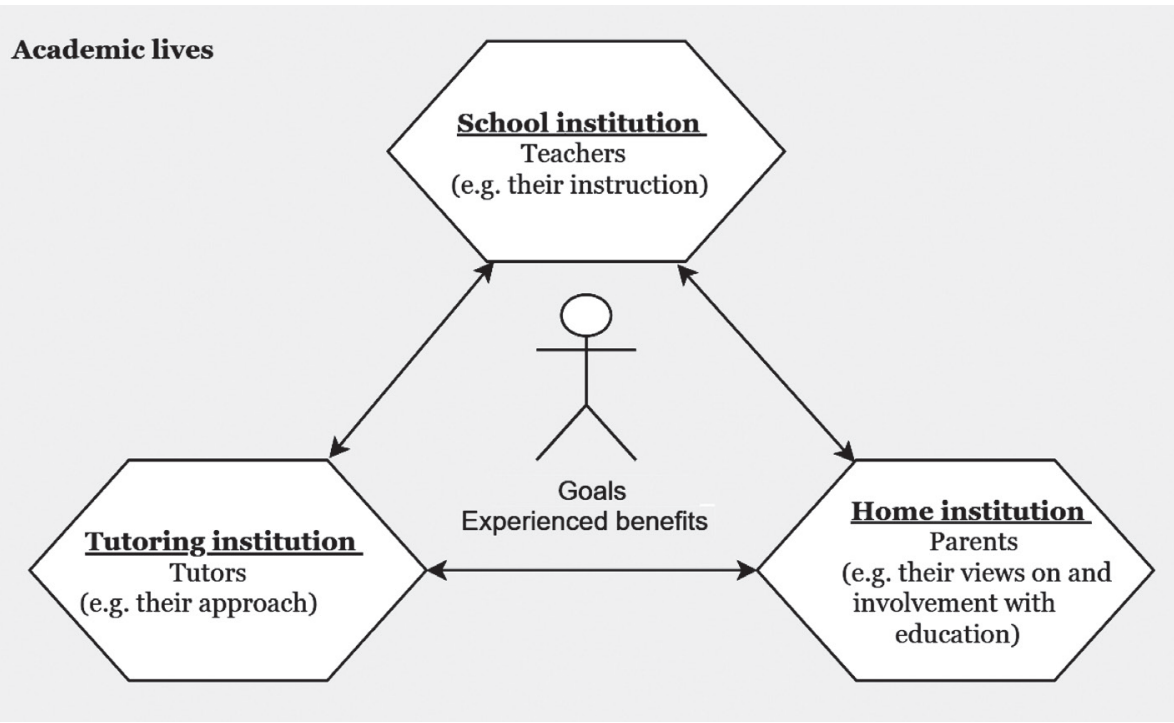

Figure 1 Conceptual framework (arrows represent interrelationships between institutions)

\subsection{Students' goals}

Previous studies have tried to map students' goals of attending shadow education by asking students about their motives for tutoring participation. Often, such motives are a reflection of what caused students to turn to shadow education in the first place. Hajar (2018), for example, found that students attended shadow education with the relatively proximal motive of passing school exams, and these findings were consistent across interview studies in Bangladesh (Mahmud, 2019), China (Yung, 2015), Israel (Addi-Raccah, 2019), and Japan (Ozaki, 2015).

Other researchers have found that students can also have less tangible goals for attending shadow education. Entrich (2015), for instance, noted that some students in Japan mostly attend private tutoring to meet peers, a finding echoed by Chan and Bray (2014). In their qualitative study in Hong Kong, Chan and Bray (2014) found that rather than focusing on academic motives, students saw tutoring as a context for communicating and interacting with their peers or tutors. Taken together, these studies indicate that students can ascribe a range of goals to shadow education.

\subsection{Experienced benefits}

In previous research, tutored students mainly reported gains in terms of knowledge (Kim, 2016), skills (Kwok, 2004; Nam \& Chan, 2019), and attitudes (Hajar, 2018). Despite these initial empirical findings, existing research has not yet provided a clear picture of the experienced benefits of shadow education attendance, particularly 
42 because such benefits differ from student to student. For instance, some students may quickly grasp the tutor's explanation, already be familiar with independent studying (Chih-Hao, 2019; de Guzman et al., 2018) or put more effort into the tutoring (Entrich, 2015; Guill \& Bos, 2014). Given such possible heterogeneity in experienced benefits, we are particularly interested in students' own descriptions of what shadow education offers them individually.

\subsection{Shadow education adding to or substituting for home and school}

In their discussion of marginalised educational spaces, Burman and Miles (2020) point to shadow education as an institution that is supposed to add to mainstream schooling, yet in practice ends up replacing some school and parental functions. If students, for instance, seek to refine already-learned study skills through shadow education, the practice adds to school. If, on the other hand, students seek extensive remedial lessons through shadow education (Bray \& Kobakhidze, 2015; Chan, 2019), the practice may compensate for shortcomings in teaching. Studying what students seek from shadow education, that they do not find at school or home, can thus be a way to explore the place of shadow education in students' academic lives. In what follows, we describe three channels - parents, teachers, and tutors - through which shadow education can either add to or substitute for the functions of home and school.

Parents, as navigators between the different institutions in students' academic lives, have been found to influence schooling in various ways (Jerrim \& Sims, 2019; Matsuoka, 2019). Parents with higher levels of schooling are, by comparison with their less-educated counterparts, more likely to be able to discuss education with their child and monitor their educational progress (Park, Byun, \& Kim, 2011). Such parents tend to also, as argued by Entrich (2015), have relatively high aspirations for their children's lives after school, which may trickle down to a student's perception that shadow education may be a necessary supplement to school (Jerrim \& Sims, 2019; Matsuoka, 2019), for instance, to improve their self-esteem (Bray \& Kobakhidze, 2015; Otto \& Karbach, 2019). Students in Hong Kong (Bray \& Kobakhidze, 2015) and Bangladesh (Mahmud, 2019) have been found to perceive parents as busy individuals who have high expectations of them but do not have time to help them with schoolwork, nor possess the ability to do so. Whereas some students may have access to academic support at home (Entrich, 2018), shadow education may be the only go-to academic support for other students (Matsuoka, 2019; Ozaki, 2015). Other research, investigating the relationship between shadow education and the home institution, points to shadow education providing parental relief, as parents trust their children to have completed their schoolwork during shadow education. In such instances, shadow education may result in fewer conflicts among family members about school work (Otto \& Karbach, 2019), possibly improving students' satisfaction with family life (Guill, Lüdtke, \& Köller, 2019), resulting in shadow education providing a benefit that the school and home cannot provide. In this study, we initiate 
the conversation on the role of parents by asking students to reflect on why they believe they (or their parents) signed (them) up for tutoring.

Teachers can constitute another channel through which shadow education can add to or substitute for the functions of schooling, for instance, when shadow education plays a role in providing more or better instruction to students who attend underperforming schools. Some students experience academic problems at school for which they blame their teachers' instruction (Mahmud, 2019), and resort to after-school tutors to find better instruction (Hartmann, 2008). The ethnographic study of Paramita (2014), for instance, shows that students saw tutors - and not teachers - as their main sources of knowledge accumulation. Given its role in knowledge accumulation, which may result in boosting their school performance, students can see shadow education as a tool that provides an advantage in competitive school systems with high-stakes testing and tracking (Park, Buchmann, Choi, \& Merry, 2016), albeit labelled by them as sometimes unfair (Hajar, 2018). In the absence of school frustrations, students can also perceive shadow education as a service providing additional instruction that builds upon the instruction of their own teachers (de Guzman, Rodriguez, \& de Castro, 2018; Forsey, 2013).

Whether shadow education adds to or substitutes teachers' instruction may also depend on the instructional quality of shadow education (Chan, 2019; Zheng, Wang, Shen, \& Fang, 2020). Guill, Lüdtke, and Köller (2019) elaborate on three dimensions of instructional quality of shadow education: structure, challenge, and support. Structure refers to the presentation of learning content. Challenge and support refer to the way the learner is activated and the tutor-student relationship, respectively. Research on students' experienced benefits of attending shadow education has revealed varying preferences in terms of tutor focus. Whereas some students appreciate that tutors focus on content-related subject knowledge (Nam \& Chan, 2019; Paramita, 2014), others value tutors that focus on memorising answers to questions listed in textbooks (Tsai \& Kuo, 2008), or predicting exam questions (Nam \& Chan, 2019). In most cases, students seem to experience the benefits of shadow education when tutors focus on lesson revision or on handling examination time and questions (Kwok, 2004). There are, however, also students who mainly appreciate tutors that are funny, inspirational, or who offer a relaxed atmosphere (Bray \& Kobakhidze, 2015).

Shadow education may also present its services by explicitly relating these to the home and school, possibly trying to ease students' school frustrations by promising to offer what students do not find in school (Hallsén \& Karlsson, 2019; Holloway \& Pimlott-Wilson, 2019). Students may, for instance, seek a distraction-free study atmosphere (Hunter \& Cox, 2014; Kim, 2016), and tutors can focus on creating such an atmosphere. Tutors can also present themselves as providers of academic and social support, or as knowledgeable mentors that provide support that teachers may not be able to provide (Forsey, 2013). Tutoring that is presented as a service to allay school frustrations can be found in advertisements in Sweden (Hallsén \& Karlsson, 2018), Israel (Addi-Raccah, 2019), Hong Kong (Trent, 2016), and Bangladesh (Hamid, Khan, \& Islam, 2018; Mahmud, 2019). 
In this study, we explore the place of shadow education in students' academic lives. As the only data on the use of shadow education in the Netherlands comes from register-based household expenditure on tutoring (CBS Statistics Netherlands, 2020) or government-commissioned research (Bisschop et al., 2019), our paper is the first empirical examination of students' experiences of tutoring in the Netherlands. Drawing on the research outlined above, we examine the place of shadow education in students' academic lives by asking students to reflect on the goals they attach to shadow education, and on the benefits they experience. We invite students to relate these goals and benefits to their school and home context (Kwo \& Bray, 2014). We formulated three research questions (RQ1-3):

- RQ1: What are students' goals when attending shadow education?

- RQ2: What benefits do students experience from attending shadow education?

- RQ3: How do students relate their goals and experienced benefits to their home and school context?

\section{Method}

We conducted individual interviews with a reflective nature (Bray \& Kwo, 2015; Pessoa, Harper, Santos, \& Gracino, 2019), in which interviewees were invited to share the goals and benefits of shadow education participation.

\subsection{Research context}

The study was conducted in the Netherlands where, upon completion of primary education, students are assigned to one of seven secondary education tracks: basic practical vocational training (praktijkonderwijs), or pre-vocational education (VMBO $B B L, V M B O G L, V M B O K B L, V M B O T L$ ), general (havo), or pre-university ( $v w o$ ) education. The latter two tracks last five and six years, respectively, while pre-vocational education lasts four years.

Policy makers, educators, and researchers in the Netherlands tend to make a distinction between one-on-one tutoring (bijles), and private tutoring in group sessions, which are often focused on generic skills and homework (huiswerkbegeleiding). A recent exploration of Dutch tutoring practices reveals that most shadow education companies adhere to this distinction, but sometimes also offer hybrid forms of shadow education that contain elements of both homework support and private tutoring (Elffers et al., 2019). We used the list of cases developed by Elffers et al. (2019) to select cases in different regions of the Netherlands. From the institutes that were willing to participate, we selected three cases that only focus on homework support, three cases that focus on private tutoring, and two cases that offer a general form of 
support. All cases featured a physical classroom. As shown in Table I, we made sure to include respondents attending a variety of tutoring practices.

Table 1 Explored Tutoring practices

\begin{tabular}{clccc}
\hline Case & \multicolumn{1}{c}{ Type } & \multicolumn{2}{c}{ Tutoring } & $n=37$ \\
\hline$\#$ & & Size & Tutors & \\
\hline 1 & Homework support & Small & (Ex-)teachers & 6 \\
2 & Homework support & Medium & NFQ & 4 \\
3 & Homework support & Large & NFQ & 5 \\
4 & Private tutoring & Small & (Ex-)teachers & 4 \\
5 & Private tutoring & Small & NFQ & 3 \\
6 & Private tutoring & Large & NFQ & 5 \\
7 & Hybrid & Medium & NFQ & 4 \\
8 & Hybrid & Medium & $($ Ex-)teachers & 6 \\
\hline
\end{tabular}

Note. Type (students used the terms huiswerkbegeleiding and bijles interchangeably), Size (Small = fewer than 50 enrolled students; Medium = between 50 and 100 enrolled students; Large = more than 100 enrolled students), Tutors (NFQ = No formally qualified teachers).

\subsection{Respondents}

The 37 respondents were all enrolled in secondary education. These students were approached through the tutoring agency in which they were enrolled. The majority of these students were boys $(n=23)$ or attended the middle-stream havo track $(n=19)$ in schools that offer more than one track. Respondents' ages ranged from 11 to 18 years old. The duration of students' participation in shadow education varied from two weeks to three years. As can be seen in Table 1, there was also heterogeneity in terms of the size of the tutoring institutes, and in the qualification of tutors.

\subsection{Data collection and analysis}

With ethical approval from the Research Ethics Review Committee at the University of Amsterdam, the first author of this paper collected data from January to June 2019. We contacted providers of shadow education directly to collect basic descriptive information on the types of tutoring offered. Data were collected using semi-structured interviews. To ensure students felt safe to speak freely, we interviewed them in an empty classroom or the corner of a library, but never in their own home or school, or in the presence of tutors, teachers, parents, or other adults. Whereas some students provided elaborate answers, others were very brief, mostly providing single-word answers, resulting in interview lengths ranging from 10 to 40 minutes. Five of the final 42 students included in our sample did not return the parental consent form, and as a result, had to be excluded from the analysis. Students 
and parents were ensured anonymity and could withdraw from the research at any time. The interviews were conducted in Dutch, and the final sample consisted of 37 students, as shown in Table 1.

An interview protocol (see Appendix A) was developed for the semi-structured interviews. The questions were about students' goals (e.g., What made you feel that you need to attend tutoring?), as well as experienced benefits (e.g., What do you know now that you did not know before and that you now know because of this tutoring?). Furthermore, the interviewer asked respondents to describe the learning activities in the physical tutoring space (e.g., Take me with you as you enter this building. What do you do here?), after which the respondent was asked to reflect upon tutoring in relation to the home and school context (e.g., What do you do or learn here that you do not do or learn at school/home?). We ensured respondents had ample time to reflect upon their own experiences.

In this study, experienced benefits refer to the value judgments students make regarding the advantages of attending tutoring (Nam \& Chan, 2019). Unlike students' goals, which are based on hopes and expectations regarding the tutoring, experienced benefits are based on actual experiences. Such experiences may, however, influence students' reflection on the goals of shadow education. We account for such conceptual overlap by asking specific questions about the utility of shadow education to the individual student (e.g., How and in what ways is this tutoring useful to you?).

To evaluate the quality of the interview protocol, we conducted a small pilot. The pilot revealed that students needed additional probing, which is why in the final interviews blank cards were used for note-taking of oft-repeated words during the interview. Afterwards, which students were asked to rank the cards according to what they considered most (to least) important. Examples of words used by students to describe experienced benefits that were written down on the cards include "better in exams" or "improve a grade" for students' goals and "planning skills" or "peace at home". We controlled for the subjectivity of the interviewer by making literal notes of what students said.

Interviews were first transcribed and then analysed with ATLAS.TI using thematic analysis (Braun \& Clarke, 2013). The first author of the paper read and re-read the transcripts to allow for familiarisation with the data. After such familiarisation, the first author coded the data to generate initial codes indicating students' goals and experienced benefits. The data was also simultaneously coded using a predefined coding scheme (Appendix B). Such a dual-coding process resulted in subthemes and higher-order themes (Figure 2). To ensure the reliability of the coding, two additional coders coded two interview transcripts and reviewed the potential themes. The coders discussed the coding process and the results. 


\section{Findings}

Figure 2 shows the thematic map extracted from the data. As the figure illustrates, students mainly expressed proximal goals (self-study, performance boost) and distal goals (career support), and formulated the benefits of attending shadow education in terms of gaining more planning skills and participating more in the classroom. Students related those goals and benefits to their school and home context mainly in referral to the amount of distractions at home, the focus of their teachers on class success instead of their individual success, and the unclear instruction of teachers. Yet, they identified their school as their primary learning context, and the home as their secondary learning context, both supplemented by shadow education. A more detailed account of students' comments is given in the following sections.

\subsection{RQ1: What are students' goals when attending shadow education?}

Some students expressed that they attend shadow education for independent (focused) studying, not necessarily in the presence of - or guided by - a tutor. As Max and Sebastian stated:

I think that the purpose of homework guidance is [...] not that it [...] takes over your schoolwork, but more to get you on the way so you can do it yourself. (Max, vwo, ninth grade)

For me, it's clear what I have to learn. So, I'm just going to work on that, and I don't really have any questions or anything. I mean, I come here to work independently. (Sebastian, havo, eleventh grade)

By providing students with a relatively silent, distraction-free place to study, the physical place in which students are tutored can serve as a cue for them to get to work. Over half of the respondents indicated using tutoring for self-study. Respondents appreciated such goals of shadow education and, in some instances, referred to shadow education using the Dutch proverb stok achter de deur ('stick behind the door', an extra inclination to work), highlighting that coming to the tutoring location may serve as a signal to complete a set of homework tasks.

Alongside turning to shadow education for self-study, students turn to shadow education to boost their performance; for instance, by preparing for an upcoming exam. Such performance-oriented goals are driven by parents' perspectives, but also come from the students themselves, as can be observed in the interactions below:

Researcher: Why do you think your mother signed you up for this tutoring?

Toby: Purely because I need a lot of help with language subjects other than English because I know English very well. So, she thought things were going even worse this year, and that's why I'm here. [...] I have a very noisy mother. She talks too much about my schoolwork. It's also nice that I can stay here every day until 6 o'clock so she can't whine all the time. (Toby, vwo, eighth grade) 


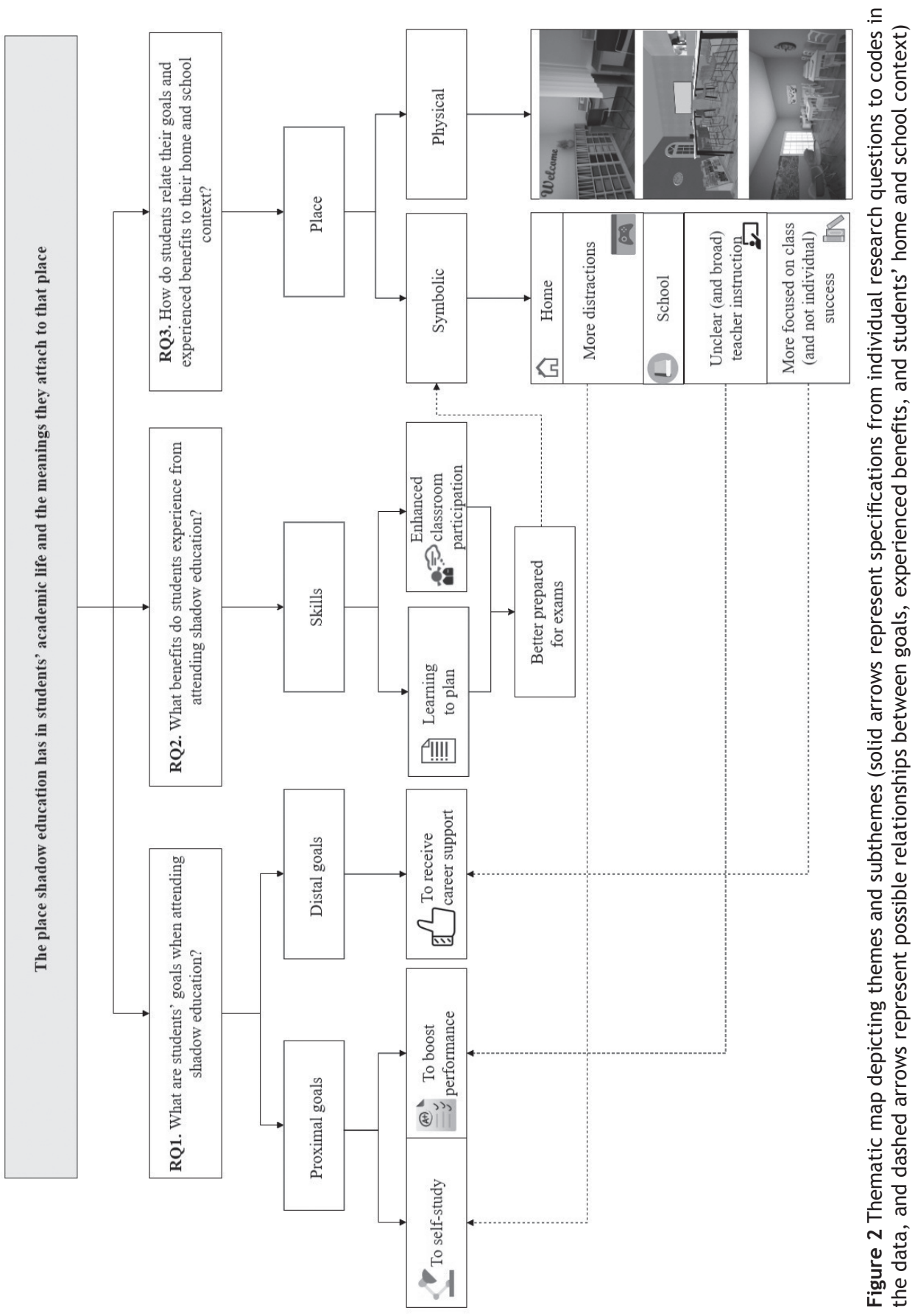


Frank: I was meant to go to vmbo-k [lower pre-vocational track], as my grades were below average, but I came here to avoid that, to get back to a normal average and now maybe I can go to havo, but I don't know that yet.

Researcher: So, coming to this tutoring, was it really to move up tracks?

Frank: Because I want to go to havo or vmbo-t [higher pre-vocational track], and not $v m b o-k b$, so that's why I came here. (Jonathan, havo, seventh grade)

Whereas the goal of boosting performance refers predominantly to short-term proximal goals (e.g., obtaining a satisfactory mark for English or attending a specific track), wishing to receive career support refers to students' perception that shadow education should bring them distal outcomes. One student, for instance, attended shadow education to seek tutoring with a view to qualifying as a medical doctor. Other students refer to such coaching in relation to attending university, as the following student commented:

I think my plan for the future is set; I just want to get my secondary education to go to university and work, so that is all fine. It's not like I'm someone who doesn't know what he wants to do, then I would be less motivated. I think the homework guidance will help me [...] this will play a role in my future. (Gabe, havo, eleventh grade)

Gabe expresses a wish to attend university and believes shadow education will help in achieving this goal. Students with a wish for career support often mentioned their tutors as individuals who are constantly available, responding promptly to instant messages or coming to the students' home to ensure they feel supported to achieve long-term goals.

\subsection{RQ2: What benefits do students experience from attending shadow education?}

Respondents unanimously stated that shadow education helps to develop exam-related skills, particularly planning skills. Furthermore, respondents perceived shadow education as equipping them to participate more actively in the classroom.

When asked what students would find difficult to do on their own if they did not attend shadow education, all but one respondent referred to planning for an upcoming exam or a school task. As the following two students commented:

Planning when I'm going to do what in a week, or how to approach my schoolwork. If I have a lot of homework, I learn how to distribute it throughout the week. [...] It starts with that: if you don't know how to organise all your homework, you also don't know when to do what, and that is very important. (Sarah, havo, tenth grade)

At the beginning of the year, I scored a four [unsatisfactory mark] for Greek and [...] not sufficient for Latin, but I picked it all up, and now I just scored very well. [...] I also think that's due to tutoring, through the learning strategies that I have learned. You keep your planner more up to date, they [tutors] also see all the tests you have, so they will remind you of that. And yes, then I usually just start in advance for those tests, and I get high marks. (Tim, vwo, eighth grade) 
In the second quote, Tim explicitly says that he scores better because of tutoring and the learning strategies he is taught at shadow education. In further conversation with Tim, he mentioned that such learning strategies include the use of sticky notes to memorise parts of the school subject or using a to-do list to work on a set of tasks during the day. In addition, improving their planning skills enables students to relax at home. Students often stressed that well-executed planning results in a sense of relief for having completed their homework during the day, as is illustrated by the following quote from Suzan:

I feel pretty proud when I go home, because I've really been productive for a couple of hours. Normally I am productive, but it all takes a long time and so on. So, I'm usually proud when I go home, and I'm also glad it's just done, because I have a lot of friends, for example, who don't start until 8 o'clock, while I start here at 4 o'clock. So, I always like that a lot, because I can't do anything in the evening, for example. I'm always very happy when I'm home. Then I can just eat and just go to bed. [...] So, I always like that very much. I always feel very satisfied when I go home. (Suzan, vwo, ninth grade)

Other benefits that were mentioned by students indicate that, due to their shadow education attendance, students find themselves participating more in the classroom, and may be more inclined to ask their teachers questions on matters they do not understand, as the following comment elucidates:

Steven: On my own, I don't ask as many questions but only when I need to. Here, I do. They [tutors] make sure you start asking questions, so because of my interaction with them, I do. I don't know; it's hard to explain. [...] I've learned here to ask questions, and because of that, I raise my hand sooner in class.

Researcher: Why is that?

Steven: I think that's because you start to see that asking for help is going to help you. (Steven, havo, tenth grade)

Echoing several other respondents, Steven explicitly mentioned that asking more questions in class occurs because of their interactions with tutors. Students, for instance, expressed that during a tutoring session tutors inspire them to ask questions on unclear matters. In some instances, tutors share their personal stories of how asking questions helped them to succeed, resulting in tutors serving as role models to the students, possibly provoking the students to set out - and work towards - certain goals.

Possibly due to their perceived improvements in planning and classroom participation, students find, since enrolling in shadow education, that they have become more effective in test-taking preparation for an upcoming exam. Various students mentioned that when an exam is nearing, tutors focus heavily on such exams; for instance, by quizzing the student. As the following comments illustrate, Tim and Thomas value such quizzing:

With geography or history, you really have to study concepts. At some point, I could do it better, I noticed, so I made progress. I thought, oh yes, but that always comes on 
the test, so I have to study that bit well, and that was what my tutor realised, so then we started to quiz those concepts here in tutoring. And afterwards, you think; yes, it makes a difference. (Tim, havo, eleventh grade)

Thomas: If I have a test, I come here, to this [shadow education] and then I ask a few things they are going to quiz me on.

Researcher: And what do you think of such quizzing?

Thomas: Good, because they [tutors] do ask specific questions which are also questions that come in the test. (Thomas, havo, seventh grade)

\subsection{RQ3: How do students relate their goals and experienced benefits to their home and school context?}

When asked about their goals and experienced benefits in relation to their home and school context, respondents described both the physical and symbolic place that shadow education occupies in their life. In doing so, students reflected on the amount of distractions at home and their teachers at school.

Physical place. The students expressing a self-study goal were also the ones reflecting on their rooms at home as unsuitable places to study, for instance, due to associations with or experiences in their room, as the following two comments from Suzan and Karen elucidate:

I've heard that it's much better for you to have, say, a place where you're really going to learn and that that's not your room, for example, because you also get negative feelings from your room or something. So, it's just nice to have a place where you can really learn or something. When I come in here, I just know, I have to work. When I enter my room, I think oh maybe I should clean up or sleep. So, I do that. (Suzan, vwo, ninth grade)

At home, it's very busy, and then I ask my parents to please be a little more quiet because I'm busy with my homework. Then they are, for example, watching TV very loudly. [...] I often have visits from nephews and nieces; they come and if I have homework, they are running around. That's not nice. I find it better here, [...] it's quiet, and I can ask the questions I want. (Karen, havo, eighth grade)

Suzan and Karen appear to value shadow education, particularly as a physical place. They appreciate the relaxed and home-like atmosphere at the tutoring place. One tutoring company's website explicitly states that a shadow education institute should feel like home. The website mentions that if students arrive after a whole day at school, tired and worn out, they should find a place where they can relax first. The tutor welcomes the students, then offers them a cup of coffee or tea, often with a snack. The students then go to study rooms, which are set up in such a way that each student place is shielded off by partitions, providing a silent place where students can study.

In their description of the physical place, some students also described their shadow education institute as a place where you sit at tables that are set up in the 
52 room, usually with a tutor providing group-based or individual instruction. Other students described and valued their shadow education institute as a place that is similar to a classroom, with tables arranged in a way that also allows for one-onone interactions between tutors and students. Figure 2 shows three illustrations of students' descriptions of shadow education as a physical place that is different from the school and the home.

Symbolic place. In addition to providing a physical place to study, shadow education appears to occupy a symbolic place in students' lives, as a meaningful place where they find the instruction and support they seek but do not find in school or at home. When asked what the difference is between shadow education and their school, one student commented: "It is actually the same as what you do at school, but then you get a more specific explanation." This comment illustrates that students may perceive that shadow education and their regular school have the same educational purpose, however in some cases tutoring is better in realising this purpose. Indeed, some tutoring places present themselves as solving the problems that students encounter at school. Alongside solving their schooling problems, students reflected on the tutors as individuals who are always there to help, even during late-night hours. Constant availability of support is unlikely to be offered by the student's school or parents, and shadow education could fill this gap in students' academic lives.

\section{Discussion}

This study explored students' goals and the experienced benefits of their participation in shadow education. By asking students what they hope to get out of shadow education (goals) and what it offers them in practice (benefits), and by asking them to relate these goals and benefits to their home and school context, we tried to unravel what it is that students seek and find in shadow education that they do not seek or cannot find in their home or school context.

With regard to students' goals when attending shadow education (Research Question 1), our data show that respondents turn to shadow education in most cases with the goal to self-study, to boost their performance, or to receive career support. In terms of the benefits of shadow education that students experience (Research Question 2), our study shows that respondents experience improvement of skills such as planning, but also that shadow education equips them to participate more actively in the classroom. Respondents' reflection of these goals and benefits in relation to their home and school (Research Question 3) indicated that respondents assign shadow education its own particular place in their academic lives. Students indicated that shadow education caters to goals that the school and home are less able to serve (e.g. distraction-free studying), and that the experienced benefits of shadow education are unique to the institution (e.g. individual support). Given that students perceive shadow education as beneficial and catering to their goals, 
the practice becomes meaningful to them, both in the physical sense - as a place to study without distractions and in the symbolic sense - as a place where they can find the support and encouragement they seek.

The distinction between the physical and symbolic place provides indications that, in the Netherlands, shadow education does not replace the place of schools or homes, but occupies its own position in students' academic lives. Such position of shadow education as a physical and symbolic place bears a resemblance to the ideas of Oldenburg (1999), who investigated the emergence of recreational spaces like cafés and libraries. Such locales, which he labels "third places", possess certain distinctive qualities that the home (first place) and work (second place) do not possess. As Oldenburg and Brissett (1982) stated, the ingredients of third places are "elusive and emergent, changing with the shifting patterns of lifestyle” (p. 270). Physical places are believed to obtain meaning (i.e. to become symbolic places) to their users if such places are conducive to their goals (Purnell, 2015). Given that the students in our study expressed that shadow education caters to their goals, we argue that shadow education can be conceptualised in line with the ideas of such a "third place".

The conceptualisation of shadow education as a third place builds upon, but does not echo, student-centred work on shadow education; for instance in the United Kingdom (Hajar, 2018, 2019), Bangladesh (Mahmud, 2019), and Israel (Addi-Raccah, 2019). Whereas in such previous studies students report relatively negative student experiences regarding shadow education and its examination-orientedness, none of the participants in our study expressed such negative experiences. The difference in results may be explained by the different schooling systems in which the research was conducted, but also by the fact that our phrasing of the questions was open, whereas previous research intentionally asked students to recall negative experiences. Our study points out that, from students' perspectives, shadow education can offer meaningful places to self-study, to receive career support, and to improve performance. Although students had ample opportunities to voice negative experiences, even discontent, with their shadow education, all respondents did not. Thus, instead of referring to their experiences with shadow education as positive or negative, students mostly embrace its benefits.

To fully understand the role of shadow education in students' academic lives, we also need an examination of the experiences of students who are not enrolled in shadow education, which we were not able to do in this study. Some of the participants did express emotions such as relief and satisfaction as a result of their shadow education attendance. Future research could examine the way that non-tutored students feel about their educational careers and opportunities in comparison to tutored students. Non-tutored students can, for instance, feel insecure about their performance and abilities when they notice that other students enrol in shadow education. To further understand such experiences, interview studies among non-tutored students would be needed. Such research can further our knowledge about shadow education as an increasingly prominent, and potentially influential, practice in students' schooling. 
Overall, this study strengthens the idea that shadow education is becoming a reality in students' academic lives, a process that policy makers, educators, and parents do not always know how to respond to. By identifying shadow educations' distinctive qualities, our study can inform and guide educational practitioners, policy makers and parents in their response to shadow education as an emerging practice that is increasingly finding a manifest place in the academic lives of students in the Netherlands, and worldwide.

\section{Acknowledgement}

This work was supported by the Netherlands Organization for Scientific Research under Grant [400-17-601]

\section{Conflict of interest}

The researchers were not involved in any of the tutoring practices and thus had no ulterior interest in obtaining particular results.

\section{References}

Addi-Raccah, A. (2019). Private tutoring in a high socio-economic secondary school in Israel and pupils' attitudes towards school learning: A double-edged sword phenomenon. British Educational Research Journal, 45(5), 938-960.

Bisschop, P., van den Berg, E., \& van der Ven, K. (2019). Aanvullend en particulier onderwijs [Supplementary and private education]. Utrecht: SEO/Oberon.

Braun, V., \& Clarke, V. (2013). Successful qualitative research: A practical guide for beginners. London: Sage.

Bray, M. (2009). Confronting the shadow education system: What government policies for what private tutoring? Paris, France: UNESCO International Institute for Educational Planning.

Bray, M., \& Kobakhidze, M. N. (2015). Evolving ecosystems in education: The nature and implications of private supplementary tutoring in Hong Kong. Prospects, 45(4), 465-481.

Bray, M., \& Kwo, O. (2015). Designing and implementing mixed approaches to shadow education research: Experiences and lessons in Hong Kong. In M. Bray, O. Kwo, \& B. Jokić (Eds.), Researching private supplementary tutoring: Methodological lessons from diverse cultures (pp. 149-178). Hong Kong: Hong Kong University Press.

Burman, E., \& Miles, S. (2020). Deconstructing supplementary education: from the pedagogy of the supplement to the unsettling of the mainstream. Educational Review, 72(1), 3-22.

CBS Statistics Netherlands. (2020). Household expenditure on homework assistance. [Data file]. Retrieved from https://www.cbs.nl/nl-nl/maatwerk/2020/04/uitgaven-van -huishoudens-aan-onderwijsondersteuning.

Chan, C., \& Bray, M. (2014). Marketised private tutoring as a supplement to regular schooling: Liberal Studies and the shadow sector in Hong Kong secondary education. Journal of Curriculum Studies, 46(3), 361-388.

Chan, V. N. M. (2019). English private tutoring in Macao: Perceptions of senior secondary three students. ECNU Review of Education, 2(1), 44-63. 
Chih-Hao, C. (2019). Effects of private tutoring on English performance: Evidence from senior high students in Taiwan. International Journal of Educational Development, 68, 80-87.

de Guzman R.M., Rodriguez S.M., de Castro B.V. (2018). The mediating role of shadow education (SE) participation on goal orientation, study habits, connectedness, and academic performance. In: Tang S., Cheah S. (Eds.), Redesigning Learning for Greater Social Impact (pp. 89-109). Singapore: Springer.

Elffers, L., Fukkink, R. G., Jansen, D., Helms, R., Timmerman, G., Fix, M., \& Lusse, M. (2019). Aanvullend onderwijs: leren en ontwikkelen naast de school [Supplementary education: learning and development next to school]. Amsterdam: University of Amsterdam.

Entrich, S. R. (2015). The decision for shadow education in Japan: students' choice or parents' pressure? Social Science Japan Journal, 18(2), 193-216.

Entrich, S. R. (2018). Shadow education and social inequalities in Japan: Evolving patterns and conceptual implications. Gewerbestrasse: Springer.

Forsey, M. (2013). But did it help you get to university? A qualitative study of supplementary education in Western Australia. In J. Aurini, S. Davies, \& J. Dierkes (Eds.), Out of the shadows: The global intensification of supplementary education (pp. 171-189). Bingley, Australia: Emerald Group.

Guill, K., \& Bos, W. (2014). Effectiveness of private tutoring in mathematics with regard to subjective and objective indicators of academic achievement. Evidence from a German secondary school sample. Journal for Educational Research Online, 6(1), 34-67.

Guill, K., Lüdtke, O., \& Köller, O. (2019). Assessing the instructional quality of private tutoring and its effects on student outcomes: Analyses from the German National Educational Panel Study. British Journal of Educational Psychology, 90, 282-300.

Guill, K., Lüdtke, O., \& Schwanenberg, J. (2019). A two-level study of predictors of private tutoring attendance at the beginning of secondary schooling in Germany: The role of individual learning support in the classroom. British Educational Research Journal, 46, 437-457.

Hajar, A. (2018). Exploring year 6 pupils' perceptions of private tutoring: Evidence from three mainstream schools in England. Oxford Review of Education, 44(4), 514-531.

Hajar, A. (2019). The association between private tutoring and access to grammar schools: Voices of Year 6 pupils and teachers in south-east England. British Educational Research Journal. Advance online publication. doi:10.1002/berj.3587.

Hallsén, S., \& Karlsson, M. (2019). Teacher or friend? Consumer narratives on private supplementary tutoring in Sweden as policy enactment. Journal of Education Policy, 34(5), 631-646.

Hamid, M. O., Khan, A., \& Islam, M. M. (2018). The spread of private tutoring in English in developing societies: Exploring students' perceptions. Discourse: Studies in the Cultural Politics of Education, 39(6), 868-886.

Hartmann, S. (2008). "At school we don't pay attention anyway": The informal market of education in Egypt and its implications. Sociologus, 58(1), 27-48.

Holloway, S. L., \& Pimlott-Wilson, H. (2019). Marketising private tuition: Representations of tutors' competence, entrepreneurial opportunities and service legitimation in home tutoring business manuals. British Educational Research Journal, 46, 205-221.

Hunter, J., \& Cox, A. (2014). Learning over tea! Studying in informal learning spaces. New Library World, 115(1/2), 34-50.

Jerrim, J., \& Sims, S. (2019). Why do so few low-and middle-income children attend a grammar school? New evidence from the Millennium Cohort Study. British Educational Research Journal, 45(3), 425-457.

Kim, Y. C. (2016). Shadow education and the curriculum and culture of schooling in South Korea. New York, NY: Palgrave Macmillan.

Kim, Y. C., \& Jung, J. H. (2019). Worldwide shadow education epidemic: From East Asia to Western Hemisphere. In Y. C. Kim \& J. H. Jung, Shadow education as worldwide curriculum studies (pp. 25-60). Cham: Palgrave Macmillan.

Kwo, O., \& Bray, M. (2014). Understanding the nexus between mainstream schooling and private supplementary tutoring: Patterns and voices of Hong Kong secondary students. Asia Pacific Journal of Education, 34(4), 403-416. 
56 Kwok, P. (2004). Examination-oriented knowledge and value transformation in East Asian cram schools. Asia Pacific Education Review, 5(1), 64-75.

Mahmud, R. (2019). Mixed implications of private supplementary tutoring for students' learning: Urban and rural disparities in Bangladesh. International Journal of Comparative Education and Development, 21(1), 61-75.

Matsuoka, R. (2019). Concerted cultivation developed in a standardised education system. Social Science Research, 77, 161-178.

Nam, Y. \& Chan, K. (2019). The roles of mainstream schooling and shadow education in English language teaching: A case study in Hong Kong. Education Journal, 8(1), 16-26.

Oldenburg, R. (1999). Great good place. New York, NY: Marlow.

Oldenburg, R., \& Brissett, D. (1982). The third place. Qualitative Sociology, 5(4), 265-284.

Otto, B., \& Karbach, J. (2019). The effects of private tutoring on students' perception of their parents' academic involvement and the quality of their parent-child relationship. Educational Psychology, 39(7), 923-940.

Ozaki, M. (2015). A juku childhood: Children's experiences in juku attendance and its relation to their well-being in Japan [Unpublished PhD dissertation]. Claverton Down: University of Bath.

Paramita, S. (2014). "We follow the private tutors not the teachers": An ethnographic insight into educational practices among the students of an Indian city. International Journal of Research in Social Sciences, 4(4), 819-840.

Park, H., Buchmann, C., Choi, J., \& Merry, J. J. (2016). Learning beyond the school walls: Trends and implications. Annual Review of Sociology, 42, 231-252.

Park, H., Byun, S. Y., \& Kim, K. K. (2011). Parental involvement and students' cognitive outcomes in Korea: Focusing on private tutoring. Sociology of Education, 84(1), 3-22.

Pessoa, A. S. G., Harper, E., Santos, I. S., \& Gracino, M. C. D. S. (2019). Using reflexive interviewing to foster deep understanding of research participants' perspectives. International Journal of Qualitative Methods, 18, 1-19.

Purnell, D. (2015). Expanding Oldenburg: Homes as third places. Journal of Place Management and Development, 8(1), 51-62.

Trent, J. (2016). Constructing professional identities in shadow education: Perspectives of private supplementary educators in Hong Kong. Educational Research for Policy and Practice, 15(2), 115-130.

Tsai, C. C., \& Kuo, P. C. (2008). Cram school students' conceptions of learning and learning science in Taiwan. International Journal of Science Education, 30(3), 353-375.

Yamato, Y., \& Zhang, W. (2017). Changing schooling, changing shadow: Shapes and functions of juku in Japan. Asia Pacific Journal of Education, 37(3), 329-343.

Yung, K. W. H. (2015). Learning English in the shadows: Understanding Chinese learners' experiences of private tutoring. TESOL Quarterly, 49(4), 707-732.

Yung, K. W. H., \& Chiu, M. M. (2020). Factors affecting secondary students' enjoyment of English private tutoring: Student, family, teacher, and tutoring. The Asia-Pacific Education Researcher, 1-10.

Zheng, X., Wang, C., Shen, Z., \& Fang, X. (2020). Associations of private tutoring with Chinese students' academic achievement, emotional well-being, and parent-child relationship. Children and Youth Services Review, 112. doi:10.1016/j.childyouth.2020.104934.

Corresponding author:

Daury Jansen,

Research Institute of Child Development and Education University of Amsterdam

Postbus 15780

1001 NG Amsterdam

The Netherlands

d.jansen@uva.nl 
A. Welcome

A1. Could you tell me more about yourself? Grade, age, hobbies?

A2. Which subjects do you enjoy? Why?

A3. What would you like to become/study later?

B. Students' goals

B1. Can you tell me when you first started to attend tutoring?

B2. Do you remember how it went? Who suggested it?

a. Why do you think your parents signed you up for this tutoring?

b. What made you feel that you need to attend tutoring?

C. Experienced benefits

C1. What do you learn here?

a. What do you know now that you did not know before and now know because of this tutoring? Could you provide an example?

b. What can you do now that you could not do before and can do now because of this tutoring? Could you provide an example?

c. How do you feel after going to tutoring?

C2. What do you think this tutoring offers you? Is it useful to you? If so, how?

D. Context

D1. School:

a. What do you do/learn here that do you do not do/learn at school?

b. Follow-up school-related questions

D2. Home:

a. What do you do/learn here that do you do not do/learn at home?

b. Follow-up home-related questions

D3. Tutoring:

a. Take me with you as you enter this building. What do you do here?

b. Follow-up tutoring-related questions

E. Wrap-up

E1. These are some notes I made during the interview.

a. Which note do you consider to be most important to you? Why?

b. If you could pick another note, which would you pick and why?

E2. Thank student and ensure anonymity. 
Appendix B: Predefined coding scheme

\begin{tabular}{|c|c|c|}
\hline Code & Subcode & Frequency \\
\hline \multirow{5}{*}{ A. Students' goals } & A1. Remediation & *** \\
\hline & A2. Wish to study & *** \\
\hline & A3. Wish to boost performance & $* * *$ \\
\hline & A4. Follow peers & * \\
\hline & A5. Attitudinal coaching & $* * *$ \\
\hline \multirow[t]{6}{*}{ B. Experienced benefits } & B1. Planning & *** \\
\hline & B2. Push in the right direction & * \\
\hline & B3. Exam preparation & *** \\
\hline & B4. Relief & $* * *$ \\
\hline & B5. Satisfaction & * \\
\hline & B6. Classroom participation & *** \\
\hline \multirow[t]{2}{*}{ C. Home } & C1. Distractions: noise & $* * *$ \\
\hline & C2. Distractions: siblings & * \\
\hline \multirow[t]{4}{*}{ D. School } & D1. (Unclear) teacher instruction & *** \\
\hline & D2. Relationships with tutors and teachers & $* *$ \\
\hline & D3. Distractions: peers & * \\
\hline & D4. Support & * \\
\hline E. Other & Open code & $* * *$ \\
\hline
\end{tabular}

Note. Frequency $=$ amount of times coded, ${ }^{*}=$ less than $5,{ }^{* *}=$ between 5 and 10 , ${ }^{* * *}=$ more than 10$)$. 